\title{
Cholangiocarcinoma and opisthorchiasis in Northeast Thailand: \\ raw fish intake may not be the sole cause
}

\author{
Viroj Wiwanitkit ${ }^{[1]}$
}

[1]. Surin Rajabhat University, Surin, Thailand.

\section{Dear Editor,}

Off late, the topic of infection-induced cancer has been of interest in regions of Northeast Thailand. Apart from uterine cervical cancer, which has been known to be correlated to human papilloma virus infection, cholangiocarcinoma is another important cancer that has been reported to be associated with trematode infestation ${ }^{(1)}$. Cholangiocarcinoma is usually a fatal cancer of the biliary tract. In the Northeastern ortheastern region of Thailand and in Laos People's Democratic Republic (PDR), where cholangiocarcinoma is highly prevalent, the association between chronic opisthorchiasis and cholangiocarcinoma has been reported. The liver fluke, also known as Opisthorchis viverrini, can be found in fresh water fish, which is a staple diet of the locals in these regions. Raw fish intake, which is the common style of eating in these areas, has been reported to be an important risk factor for chronic opisthorchiasis and cholangiocarcinoma. Chronic inflammation due to biliary parasitoses is considered to be an underlying cause of carcinogenesis ${ }^{(2)}{ }^{(3)}$. Dietary contamination with nitrosamines and opisthorchiasis has been reported to be strong predisposing factors for cholangiocarcinogenesis ${ }^{(4)}$. The famous raw fish dishes in the endemic area are prepared by adding nitrosamine. Hence, the risk of contamination by both the liver fluke parasite and nitrosamine is high. Although government of Thailand runs a campaign intended at curbing this disease, the problem continues to exist.

Since intake of raw fish has been mentioned as an important cause of trematode infestation-induced cholangiocarcinoma, several studies have focused on parasitic contamination in the intermediate hosts of liver fluke, such as snails and fishes, in the endemic area. In this letter, the author would like to report the results of one such study and extrapolate an interesting new insight from the observation. The study was conducted in Hauytalaeng district located in Nakhon Ratchasima province in the Northeastern region of Thailand; this area has the highest prevalence of cholangiocarcinoma. A survey on parasitic contaminations in the intermediate hosts of liver fluke, i.e.,

Corresponding author: Prof. Viroj Wiwanitkit. Surin Rajabhat University. Wiwanitkit House, Bangkhae, Bangkok, 10160 Thailand.

e-mail: wviroj@yahoo.com

Received 18 March 2015

Accepted 13 April 2015 snails and fishes, and on parasitoses among the local people was conducted ${ }^{(5)(6)(7)}$. The results revealed the absence of liver fluke among intermediate hosts, and $5.5 \%$ of the local people were reported to have had liver fluke-induced parasitoses ${ }^{(5)(6)(7)}$. This finding is of importance because if the infestation rate in local people is high, the contamination rate in intermediate hosts should have also been high. Hence, propagating consumption of cooked fish dishes might not be the sole solution for the problem. In fact, due to industrialization and modernization, the locals consume food from other remote non-local sources, and thus, the surveillance of intermediate host contamination might not be useful for disease control. Undeniably, several other factors, such as food contaminated by pesticides, can also cause liver fluke-induced carcinogenesis, resulting in chronic opisthorchiasis $^{(8)}$.

\section{CONFLICT OF INTEREST}

The author declare that there is no conflict of interest.

\section{REFERENCES}

1. Wiwanitkit V. Clinical findings among 62 Thais with cholangiocarcinoma. Trop Med Int Health 2003; 8:228-230.

2. Rizvi S, Gores GJ. Pathogenesis, diagnosis, and management of cholangiocarcinoma. Gastroenterol 2013; 145:1215-1229.

3. Razumilava N, Gores GJ. Cholangiocarcinoma. Lancet 2014; 383:2168-2179.

4. Pairojkul C, Shirai T, Hirohashi S, Thamavit W, Bhudhisawat W, Uttaravicien T, et al. Multistage carcinogenesis of liver-flukeassociated cholangiocarcinoma in Thailand. Princess Takamatsu Symp 1991; 22:77-86.

5. Wiwanitkit V, Suwansaksri J, Chaiyakhun Y. High prevalence of Fasciolopsis buski in an endemic area of liver fluke infection in Thailand. Med Gen Med 2002; 4:6.

6. Nithiuthai S, Suwansaksri J, Wiwanitkit V, Chaengphukeaw P. A survey of metacercariae in cyprinoid fish in Nakhon Ratchasima, northeast Thailand. Southeast Asian J Trop Med Public Health 2002; 33 (suppl III):103-105.

7. Kaewpitoon SJ, Rujirakul R, Kaewpitoon N. Prevalence of Opisthorchis viverrini infection in Nakhon Ratchasima province, Northeast Thailand. Asian Pac J Cancer Prev 2012; 13:5245-5249.

8. Wiwanitkit V. Pesticides, fresh water fish, liver flukes and nitrosamines: A story of cholangiocarcinoma development in Thailand. Asian Pac J Cancer Prev 2009; 10:961-962. 